\title{
Medios de comunicación y \\ transformación de la familia
}

Javier Esteinou Madrid*

Departamento de Educación y Comunicación, Universidad Autónoma Metropolitana-Xochimilco

\section{Televisión y política culturales}

Tradicionalmente, el diseño y la reflexión sobre políticas culturales en México se han caracterizado por considerar las problemáticas de los campos educativo, museográfico, arqueológico, etnográfico, operístico, dancístico, musical, literario, etc., pero sistemáticamente no han incluido la de los medios de comunicación. Esta omisión por una parte, ha dejado una laguna esencial en el terreno educativo del país que ha generado un alto costo espiritual, y por la otra, ha provocado una enorme contradicción entre lo que se siembra en la escuela por la mañana y lo que se destruye cognitiva y afectivamente por la tarde y noche, a través de los medios de comunicación al introducir una violencia cultural.

Así, en primer término, al asentar las políticas culturales sin incorporar los modernos medios de comunicación, el sector intelectual del país sólo ha pintado la sombra del problema y no toca la esencia de la realidad que vivimos en la sociedad mexicana contemporánea. Es decir, se aborda la realidad cultural del México del siglo XIX, en el que no existía la comunicación de masas, y no la de finales de este siglo donde constatamos que si algo ha cambiado tajantemente la realidad ideológica del país después de la Conquista Española, la acción de la Iglesia y de la intervención del aparato educativo en nuestra sociedad, es la presencia de los medios electrónicos de información. Es más, se puede decir que en las generaciones actuales de niños y jóvenes existe una mentalidad, una sensibilidad y una imaginación nacionales diferentes, antes y después de la aparición de los canales de comunicación colectivos, particularmente de la radio y la televisión. 
Medios de comunicación y transformación de ...

En segundo término, al pasar por alto esta realidad se ha permitido flagrantemente que la educación que el Estado mexicano imparte con muchísimos esfuerzos sea borrada por los medios de comunicación, en especial, la televisión.

Con ello, el sector intelectual "incluso crítico" dedicado al examen de los procesos de comunicación y cultura nacionales ha ignorado que el surgimiento de los medios colectivos de información no sólo han transformado radicalmente la estructura mental de nuestra sociedad civil, sino que han creado una nueva dimensión ideológica del Estado nacional, vía la moderna extensión cultural de éste a través de los apartados de información. Esto significa que, con la presencia de los medios de comunicación, sobre todo con la actuación de la televisión, el Estado mexicano ha sufrido una gran mutación, pues sus tareas de construcción, dirección y cohesión ideológica se ha extendido y dado origen a una nueva faceta del poder nacional: el Estado Ampliado Mexicano.

Este flamante Estado Ampliado se ha caracterizado porque gracias a los apoyos tecnológicos que le brindan los canales de información, ha conquistado una gran capacidad orgánica para realizar de manera más competente sus funciones culturales como instancia rectora de la sociedad. Por esto, el nacimiento y la expansión de esta nueva zona del Estado Ampliado Mexicano se encuentran en íntima correspondencia con la evolución y organización que adopta cada nuevo sistema y proceso de comunicación aparecido en nuestro territorio.

Pero las implicaciones de la presencia de este moderno Estado Ampliado en nuestra sociedad, no sólo abarca la transformación de la estructura del Estado, sino que también ha producido, en los últimos setenta años, un silencioso cambio drástico en la correlación de fuerzas culturales que han delineado el proyecto ideológico del pais, pues ha hecho posible la rápida y fuerte acción de nuevos grupos en la esfera cultural: el privado y el transnacional. Así, las fracciones monopólicas privadas supranacionales en poco tiempo han propiciado un cambio mental y han construido e internalizado en la población, especialmente infantil y juvenil, otro proyecto cultural de sociedad, diferente al que por decenios ha planteado el Estado tradicional.

De esta manera, la capacidad de educación y de dirección de la sociedad que el Estado mexicano ganó a través de las armas durante la Revolución de 1910, hoy se ha perdido aceleradamente por no aplicar un control cultural sobre los medios electrónicos de comunicación. En otras palabras: el espíritu, la utopía y la visión del hombre que creó el movimiento insurgente de principios de siglo rápidamente se perdió por la oficialización que el Partido Revolucionario Institucional (PRI) hizo de este movimiento y porque el proceso de industrialización surgido en el país desde 1920 creó, primero a través de la 
radio y después de la televisión, una esperanza denominada "consumo" que con el tiempo se ha convertido en la religión moderna, particularmente en las ciudades.

De esta forma, al permitir el Estado mexicano que los medios de comunicación fueran dirigidos desde su origen por los fenicios de las ondas hertzianas y al conceder que éstos se desarrollaran con una autonomía ideológica casi absoluta, autorizó ala mismo tiempo que se perdiera nuestro proyecto cultural, que es el único respaldo que le sirve de base para gobernar como Estado nacional. Esto debido, a que la intencionalidad marcadamente mercantilista de los medios de comunicación ha recorrido y anulado con gran rapidez la frontera ideológica del país, que es nuestro principal dique mental para sobrevivir como nación autónoma frente al mundo externo. Así, hoy hemos adquirido otra forma de ver al ser humano, al mundo, al universo y a la vida sin ser estas las bases culturales que requiere nuestra sociedad para avanzar y crecer.

\section{Capacidad persuasiva de la televisión}

Dentro de este contexto de evolución de las sociedades modernas es necesario considerar que la televisión se ha convertido en el principal medio de comunicación colectiva de nuestra civilización, ocupando un papel central en el desarrollo de las mentalidades y sensibilidades; y por lo tanto, en el desarrollo del país.

Hoy día la televisión se ha convertido en el sistema nervioso fundamental del avance o retroceso de nuestra cotidiana cultura nacional. ${ }^{1}$

Por ello, aunque estamos conscientes que la televisión no produce efectos automáticos sobre el auditorio. Que no es una aguja hipodérmica que inyecta mecánicamente sus contenidos en los cambios de la población. Que existen múltiples formas de interpretar por parte del auditorio los mensajes televisivos que recibe. Que por parte de los emisores no existen efectos acabados sobre los auditorios como hemos creído en años anteriores. Que no es omnipotente para producir procesos mágicos. Que normalmente refuerza tendencias previamente ya existentes en el seno de las comunidades. Que la conciencia humana no solamente se produce por la acción simbólica de la televisión, sino por un conjunto más amplio de relaciones sociales y de redes culturales que impactan sobre la

1 Para comprender porqué la televisión se ha convertido en el principal medio de comunicación en la sociedad contemporánea, consultar nuestro trabajo: Los medios de comunicación y la construcción de la hegemonia, Editorial Trillas, México, D.F., 1992, 200 páginas. 
Medios de comunicación y transformación de ...

inteligencia y la sensibilidad de los individuos. Que su efectividad de convencimiento no depende totalmente de las imágenes que se transmiten sino de otro procesos sociales complementarios, etcétera.

También sabemos que, a través de las propiedades físicas que ha conquistado y de los hábitos culturales que ha formado, la televisión cuenta con un alto margen dẹ eficacia persuasiva comprobada para crear y cambiar las formas de pensar y actuar en México.

En la actualidad debemos tener presente que en nuestro país, frente a la tradicional acción del sistema escolar y religioso, la televisión se ha convertido en la principal red educativa capaz de cambiar, con mayor rapidez y agilidad, los valores, las actitudes, los hábitos y las conductas de los receptores. En una idea, dirige la cultura cotidiana en cada sexenio de gobierno.

Así, la televisión se ha convertido en el principal mediador cultural, a través del cual el Estado articula ideológicamente a nuestra sociedad, convirtiéndose en la principal organizadora colectiva de la historia moderna de México.

Sin embargo, esta mediación central que ejerce la televisión entre gobierno y sociedad, no significa, en ningún momento, que la capacidad de persuasión que realiza sea omnipotentemente eficaz para convertir en socialmente dominante cualquier mensaje transmitido por ésta y mecánicamente doblegar las conciencias y las acciones de todos los ciudadanos que son tocados por ésta.

La fuerza de convencimiento de la televisión tiene límites de competencia muy precisos, $y$ los principales son los tres siguientes:

- Primero, las informaciones televisivas que leen, decodifican e interiorizan los receptores nunca se asimilan homogéneamente en todos ellos con el mismo signo ideológico e intensidad personal con la que se emiten, sino que varían según son sus situaciones históricas, antropológicas, religiosas, económicas, familiares, políticas, culturales, materiales, regionales, étnicas, productivas, etc., que los determinan como seres humanos. No debemos olvidar que los públicos no son pasivos, ni neutros, ni socialmente vírgenes, sino que éstos practican sus propias experiencias de vida y sus inserciones sociales. $^{2}$

2 Por otra parte, es alarmante y aleccionador para la sociologia crítica del estudio del receptor, que quienes con mayor exactitud, sutileza y eficacia conocen el perfil de comportamiento del auditorio es el sector dominante, que impulsado básicamente por el capital industrial y comercial, se dedica, a través de las 
- Segundo, la habilidad seductora de la televisión nunca puede rebasan el peso de la realidad que enfrentan los espectadores, pues siempre las circunstancias de sus vidas concretas son más fuertes que el poder que alcanza la información y las imágenes audiovisuales que se difunden. Es necesario subrayar que la televisión no sustituye a la dinámica económica, política y social, sino que la apoya o debilita con base en los proyectos globales que existen detrás de ésta. De lo contrario, sobrevalorariamos el papel de la televisión al otorgarle fantasiosamente una absoluta propiedad transformadora, cuando en verdad sólo es una tecnología muy perfeccionada de promoción de intereses o políticas precisas.

- Tercero, cuando la gama de discurso que transmite la televisión encuentra las condiciones psicológicas favorables en los campos de conciencia de los públicos, éstos son asimilados en un alto porcentaje y viceversa.

Sin embargo, no obstante la existencia de diversos límites reales en la tarea de mediación social que realiza la televisión entre pueblo y gobierno, su capacidad de persuasión y de movilización de la población en el país ha sido tan eficiente en diversos momentos, que ha generado fuertes fenómenos sociales de signos contrarios. Así, por ejemplo, en un sentido positivo constatamos cómo a través de las acciones promocionales de la televisión, se ha colaborado a reducir en la década de los ochenta la tasa de crecimiento demográfico del $4.3 \%$ al $2 \%$ construyendo un nuevo modelo cultural de familia basado en cuatro miembros: padre, madre y dos hijos. De igual forma, se ha contribuido a alfabetizar y a otorgar instrucción básica a través de la telesecundaria a miles de mexicanos, a tal grado, que de 1983 a 1987 se redujo el índice de analfabetismo en sujetos mayores de 15 años del 14 al 7.1\%, alfabetizando a más de 3 millones 300 mil mexicanos. Esto significa que hay 92 de cada 100 mexicanos adultos que ya saben leer y escribir en el país.

técnicas de la mercadotecnia y publicidad, a radiografiar los diversos patrones de aspiraciones, gustos, comportamientos, debilidades, actitudes, preferencias, inclinaciones, etc., del receptor, con objeto de integrarlo al proyecto de desarrollo del capital nacional e internacional. Javier Esteinou Madrid, El estudio materialista de la comunicación de masas, Cuadernos del тісом No. 1, Taller de Investigación para la Comunicación Masiva, Departamento de Educación y Comunicación, Universidad Autónoma Metropolitana, Unidad Xochimilco, marzo de 1979, p.9.

3 Hoy 92 de cada 100 adultos mexicanos sabeh leer y escribir, Excelsior, 13 de diciembre de 1986; Reconocimiento de la UNESCO al gobierno mexicano por los resultados de programas de alfabetización, Uno Más Uno, 9 de septiembre de 1987; Descendió el analfabetismo a 7.6\%, Uno Más Uno, 27 de marzo de 1987. 
De la misma manera, ha logrado promover permanentemente la donación altruista de sangre a hospitales y bancos de plasma. ${ }^{4}$ Asimismo, con apoyo de las campañas de prevención médica vía televisión, las acciones del sector salud, la participación de 600 mil voluntarios y la instalación de 80 mil puestos de vacunación, se pudo inmunizar en dos fines de semana de 1987 en todo el territorio nacional a más de 12 millones de niños contra la poliomielitis, a 10 millones de pequeños contra la difteria y la tosferina, y a 2 millones de niños contra el sarampión, que en conjunto han alcanzado reducir en más del 35\% las enfermedades infantiles en la República. ${ }^{5}$

También, por la acción instructiva de la televisión y otros medios de comunicación, se ha formado en los últimos dos sexenios una nueva cultura financiera de masas que ha logrado crear una base de educación económica que permite que la clase mediay algunos sectores de la clase popular sepan cómo invertir sus ahorros en diversos instrumentos de capitalización, como son plazos bancarios a una semana, un mes, tres meses, seis meses, en renta variable, papel comercial, petrobonos, acciones de empresas, etc. En los mismos términos, en los spots televisivos transmitidos de 1984 a 1985 consiguieron abarrotar los Registros Civiles del país para regularizar las uniones libres de las parejas y registrar oficialmente a sus hijos. En idéntico sentido, la repetición publicitaria a través de la televisión ha creado en las ciudades desde hace 15 años a la fecha una cultura de uso de la toalla sanitaria que las mujeres urbanas, y se nota cada vez más con marcada claridad, que también ya empieza a surgir en el campo.

Igualmente, se logró que los ciudadanos hicieran valer más sus derechos como compradores mediante la educación televisiva que ha proporcionado el Instituto Nacional del Consumidor y la Procuraduría Federal del mismo en los últimos 12 años. ${ }^{6} \mathrm{De}$ igual forma, se obtuvo que a través de la promoción televisiva más de 80 mil pedalistas participaran en 1987 en el Paseo Ciclista de la Constitución, 15 mil atletas asistieron a

4 Respuesta al festival del donador altruista de sangre, Excelsior, 14 de octubre de 1987.

5 Las campañas de vacunación han logrado reducir 35\% las enfermedades infantiles, Excelsior, 12 de marzo de 1986; El próximo sábado la segunda jornada de vacunación antipolio, Excelsior, 22 de marzo de 1986; Serán inmunizados contra la polio más de doce millones de niños, Excelsior, 14 de enero de 1987; Millón y medio de niños serán vacunados contra la polio en el D.F., Excelsior, 21 de enero de 1987; Aplicarán hoy a 12 millones de infantes la vacuna antipolio, Excelsior, 24 de enero de 1987; Se inmunizó contra la polio a 12 millones de infantes, Excelsior, 25 de enero de 1987; Aplicó la armada 75 mil dosis de vacuna antipolio, Excelsior, 29 de enero de 1987; Vacunados más de 10 millones de niños contra difteria y tosferina, Excelsior, 23 de mayo de 1987; Del 26 al 30, vacunas contra el sarampión: SSA, Uno Más Uno, 20 de octubre de 1987.

6 Cada vez más consumidores hacen valer sus derechos: Pliego Montes, Excelsior, 11 de febrero de 1987. 
la Sexagésima Tercera Carrera de la Constitución en el D.F. y 4 mil deportistas estuvieran presentes en el IV Maratón Deportivo Guadalajara. ${ }^{\text {? }}$

También a partir de la difusión de la propaganda audiovisual sobre la prevención de los accidentes de trabajo y la capacitación de aproximadamente un millón de funcionarios públicoș por el Instituto Mexicano del Seguro Social, se obtuvo que los percances de trabajo en las empresas se redujeran el años pasado en $57 \%$. ${ }^{8}$ En idéntico sentido, a través del incremento de las campañas publicitarias, en $80 \%$ en prensa, $110 \%$ en revistas, $85 \%$ en radio y $200 \%$ en televisión, la iniciativa privada pudo sostener la demanda de consumo de la población en .ciertos renglones excepto el sector textil, la industria zapatera y la industria automotriz que fueron afectadas drásticamente por la crisis económica de 1987. ${ }^{9}$ Asimismo, mediante la promoción televisiva y la preparación de 450 mil promotores del voto por parte de la Federación de Trabajadores al Servicio del Estado se logró que el $\mathbf{8 5 \%}$ de los ciudadanos en edad de votar se registraran voluntariamente en el Padrón Electoral para participar en las elecciones presidenciales de $1988 .{ }^{10}$

Igualmente, otro caso sumamente meritorio de persuasión y movilización de la sociedad mexicana ocurrió ante los terremotos de 1985, donde a través de la televisión y otros medios de comunicación, el conjunto social se sensibilizó de la magnitud de la tragedia y logró vincular las urgentes demandas de socorro con los ofrecimiento de ayuda voluntaria de los ciudadanos, creando un movimiento de solidaridad civil que no se había presenciado en las últimas cinco décadas. ${ }^{11}$

Mediante otras acciones persuasivas la televisión nos ha reeducado cotidianamente para sustituir en nuestro registro de domicilio la colonia por el código postal. Para agregar otra cifra cabezal por zonas cuando el número telefónico rebasó los seis dígitos. Para aceptar las nuevas instalaciones en nuestro hogar que permitieron el cambio de voltaje de 120 a 110 volts. Para cambiar las placas al nuevo sistema de referencia permanente.

7 Almaratón de Guadalajara 4,000 corredores, Excelsior, 4 de febrero de 1987; 15,000 atletas en la carrera de la Constitución, Excelsior, 8 de febrero de 1987; El paseo ciclista, un freno a la contaminación, Excelsior, 5 de junio de 1987.

8 Bajaron los accidentes laborales en 57\%: MSS, Excelsior, 10 de febrero de 1987.

9 Reconoció MMH el apoyo publicitario a las campañas del sector público, Excelsior, 29 de septiembre de 1987.

10 Está preparando al FSTSE a 450,000 promotores del voto, Excelsior, 2 de julio de 1987.

11 Esteinou Madrid, Javier, La reconstrucción y los medios de comunicación, El Búho, No. 15, suplemento cultural de Excelsior, 22 de diciembre de 1985; Esteinou Madrid, Javier, Televisión y memoria social (dos partes), El Búho, Nos. 35 y 36, Excelsior, 11 y 18 de mayo de 1986. 
Para pagar los impuestos de las personas físicas y morales en las fechas indicadas. Para obtener nuestras nuevas credenciales de elector, etcétera.

Por otro lado, en un sentido negativo presenciamos cómo la televisión ha propiciado a lo largo de los años un permanente ciclo consumista que provoca el desperdicio de gran parte de la energía de nuestra sociedad. A través de las imágenes que diariamente se difunden, constatamos cómo la televisión reconstruye en la pantalla otro país que no es México. De igual forma, mediante los valores televisivos que se proyectan, observamos cómo la televisión ha generado un fuerte corrimiento de la frontera ideológica nacional que ha propiciado la desmedida admiración por el estilo de vida y éxito norteamericanos y el rechazo a los netamente local, etcétera.

\section{Televisión y violencia}

El gran desarrollo tecnológico que ha alcanzado la industria audiovisual comprueba la gran capacidad transformadora de concepciones y hábitos de los ciudadanos que posee la televisión en nuestro país. Esta capacidad persuasiva se amplifica mas cuando sabemos, por una parte, que dicha institución audiovisual se ha convertido en una fuente muy importante de conocimientos cotidiano de la realidad, especialmente en las comunidades humanas urbanas; y que por otra parte, el promedio de exposición de la familia mexicana a la televisión es superior a 49.5 horas por semana y esta práctica va en aumento con los nuevos sistemas de televisión por cabe y suscripción a domicilio. ${ }^{12}$ Este poder real que ha conquistado la televisión mexicana sobre los campos de conciencia de los diversos auditorios nacionales es el que a lo largo de su aplicación a través de varias décadas ha producido en el país múltiples fenómenos culturales de diverso signo, entre los cuales, destacan la generación de diversas clases de violencias sobre los telespectadores, como son la violencia por exposición y la violencia por omisión.

El primer término, en relación a la violencia por exposición constatamos que la televisión a través de la difusión de su enorme gama de programas agresivos ha contribuido a crear un clima favorable para la expansión de la agresividad al interior de la sociedad. Por ejemplo, al terminar la enseñanza secundaria un joven normal ha pasado frente al televisor el doble de tiempo del que mantuvo como asistencia a la escuela, o sea

12 La violencia televisada produce graves y prolongados daños siquicos en los niños. Excelsior, 8 de agosto de 1992. 
nueve años. En dicho lapso su cerebro habrá registrado las imágenes de aproximadamente 150,000 episodios violentos y unas 25,000 muertes. $^{13}$

Incluso, dicha realidad se ha incrementado al grado que en los Estados Unidos se calcula que actualmente las imágenes violentas aparecen a razón de 25 veces por hora. ${ }^{14}$ Por ello, tenemos que preguntarnos e investigar, si nuestra televisión nacional importa en un alto porcentaje la programación norteamericana, especialmente en esta fase de globalización e internacionalización cultural en la que ha entrado el país ¿Cuántas escenas violentas se están recibiendo en nuestros hogares mexicanos que cuentan con una legislación y práctica normativa más abierta, liberal y corrupta que la anglosajona? ¿Qué efectos está causando ese caudal informativo sobre nuestras nuevas generaciones en etapa de formación psíquica y espiritual?

Frente a este panorama debemos de tener presente que en los paises altamente industrializados se ha comprobado que en la medida en que aumenta la exposición de suicidios en las imágenes televisivas, también se eleva el porcentaje de suicidios entre jóvenes y niños de las comunidades humanas; o en la medida en que se incrementan las exposiciones de contenidos con violaciones sexuales al sector femenino, se expande en la sociedad las agresiones sexuales a las mujeres.

Por otra parte, hay que considerar que "el impacto mental que el crimen televisado provoca en cualquier espectador, constituye una simulación peligrosa. Los adultos se pueden defender más de estas fantasías, pero los niños y jóvenes, dan por hecho que un fuerte garrotazo en la cabeza de un contrincante le hace caer de forma muy chistosa y además se repone fácilmente del dolor. Por ello, es necesario que los padres les enseñen a los hijos este tipo de alteraciones de la realidad.

Deben explicarles, por ejemplo, que un golpe en la cabeza de un ser humano puede provocarle un daño irreparable. Que el respeto a la integridad física de los demás es un deber fundamental y que la violencia es el estado más deplorable de la conducta humana". ${ }^{15}$

El segundo término, en relación a la violencia por omisión encontramos que la televisión ha producido otro tipo de agresión que ha sido la espiritual, pues ha impuesto

13 La violencia televisada produce graves y prolongados daños siquicos en los niños, Excelsior, 8 de agosto de 1992.

14 La televisión sin cerillos quemó una casa, Excelsior, 7 de noviembre de 1993.

15 La violencia televisada produce graves y prolongados daños siquicos en los niños, Excelsior, 8 de agosto de 1992. 
gradualmente sobre la conciencia del pais otro proyecto cultural distinto al de nuestras bases psíquicas milenarias. En este sentido, podemos decir que el Estado mexicano está profundamente extraviado en su proyecto cultural, pues ha permitido la construcción de un programa mental, que por medio de la televisión, está formando generaciones de hombres enanos, ya que nos ha hecho creer que lo importante en la vida son los valores intranscendentes de la frivolidad y el consumo, y no los principios del reconocimiento, la autoestima, la aceptación del otro y el crecimiento personal. La televisión ha colocado el éxito del individuo en la capacidad que tiene para adquirir y acumular bienes, y no en la facultad para desarrollar su interior y aumentar su capacidad de amar.

Por todo lo anterior, no obstante que en la actualidad contamos con una mucho mayor cantidad de recursos tecnológico-comunicativos, sabemos cada vez menos de nosotros como país y como seres humanos, y estamos perdiendo nuestra identidad nacional. Hoy, la televisión reproduce a colores una nueva visión de los vencidos.

Esto significa, que en la actualidad la principal fuerza educativa que guía a nuestra sociedad ha sido desplazada del tradicional sistema educativo a la red de los medios de comunicación de masas. Por esto, hoy día la verdadera dirección ideológica de nuestra sociedad ya no se construye cotidianamente desde el aula y otras instituciones culturales, sino desde los canales colectivos de información, y en particular desde el aparato televisivo.

De esta forma, el modelo mental que los medios imponen, ha acelerado el rompimiento de la relación trigeneracional que se establecía entre hijos-padres,abuelos, principal sostén de este país en los últimos 400 años. Así, en menos de una generación, en nuestras conciencias se ha sembrado masivamente lo transnacional estadounidense, al grado de que hoy podemos decir como lo hace Carlos Monsivais- que en el territorio mexicano ya nació la primera generación de estadounidenses. Hemos perdido la memoria de nuestro proceso histórico y, en menos de cuatro decenios, hemos adquirido la memoria de lo multinacional.

Todo lo anterior se confirma cuando observamos que los niños mayores de seis años conocen más la información televisiva que la transmitida en la escuela primaria. Por ejemplo, en el terreno de la realidad nacional el $77 \%$ de los pequeños retienen más frases como "La chispa de la vida" o "Recuérdame" y sólo el $49 \%$ conserva otras como "! Viva la Independencia j", "La solución somos todos" o "El respeto al derecho ajeno es la paz". De igual manera, mientras que casi la totalidad de los niños (92\%) retiene la imagen del Gansito Marinela, menos de dos terceras partes (64\%) identifica la Columna de nuestra Independencia o al cura Hidalgo. El $63 \%$ de los niños asocia fácilmente el tema de la 
tarjeta de crédito "Carnet" y sólo el $43 \%$ reconoce la frase "El respeto al derecho ajeno el la paz". En resumen, observamos que de cada diez personajes que los niños identifican, sólo tres son de la historia de México.

En el campo de la historia, el $67 \%$ de los niños identifican los días y horarios en que se tranșmiten sus programas favoritos de televisión, acontecimientos más significativos de la historia nacional. Los super héroes de la televisión como "La mujer maravilla", son más conocidos por los pequeños (98\%) que los héroes de la Revolución Mexicana (33\%). "El Chapulín Colorado" es más evocado por los infantes (96\%) que los Niños Héroes de Chapultepec (82\%). "Superman" está más presente en la mente de los pequeños (97\%) que Don Benito Juárez.

En materia religiosa, no obstante que nuestra sociedad es acentuadamente católica, más de la mitad de los niños (56\%) conoce el día en que se transmitía "Hogar dulce hogar", mientras que sólo el (86\%) recuerda el día en que se celebra la Navidad. Mientras el $55 \%$ de los niños puede decir qué día se difundía el programa "Mis huéspedes", sólo el $32 \%$ sabe la fecha en que se celebra la fiesta de la Virgen de Guadalupe. Los pequeños identifican mejor el logotipo de "Sabritas" (86\%) que una hostia (46\%).

En el área cívica, el $\mathbf{8 7 \%}$ de los infantes conoce los días en que se transmiten los programas cómicos y sólo el $13 \%$ sabe la fecha en que toma posesión el Presidente de la República. Sólo el $8 \%$ conoce la fecha en que el primer mandatario rinde su informe anual, mientras que el $61 \%$ sí puede decir el día y la hora en que aparecen las series fantásticas. El 83\% de los niños identifica el logotipo de los pastelitos rellenos y sólo el 63\% conoce el Calendario Azteca. Mientas que el $81 \%$ de los pequeños evoca el logotipo de los productos "Marinela", sólo el 66\% identifica el escudo nacional. Las tres cuartas partes (77\%) de los niños identifican la imagen de Chicles Adams y menos de una quinta parte (17\%) reconoce el Monumento a la Revolución. Finalmente, el logotipo de los chocolates "Carlos V" es más reconocido (77\%) que el Monumento del Angel o la columna de la Independencia $(40 \%)^{16}$.

Incluso, este panorama está por agravarse aún más por la apertura de nuestra economía al comercio internacional, dado el ingreso de México al GATT y su incorporación al Tratado Norteamericano de Libre Comercio con Estados Unidos y Canadá.

16 La televisión y los niños. Conocimiento de la realidad televisada vs. conocimiento de la realidad nacional, Cuadernos del Consumidor, Instituto Nacional del Consumidor (INCO), México, D.F., noviembre de 1982. 
Medios de comunicación y transformación de ...

Si éstos son sólo algunos de los rasgos del retroceso de la identidad nacional que se experimenta en nuestro país, especialmente, en los niños, nos preguntamos ¿por qué la televisión se esfuerza diariamente en concentrar mayoritariamente la energía mental de la nación a través de sus horarios triple A ( 7 a 10 de la noche) en hacer propaganda de cigarros, brandyes, rones, "alimentos chatarra", perfumes, etcétera, y no en fortalecer nuestras bases de reconocimiento e integración cultural como nación y comunidades humanas?

Por otra parte, si sabemos que cada niño que nace en México trae un compromiso heredado de más de 750 millones de pesos por concepto de deuda externa. Si cada vez más son los pequeños que intentan cruzar el río Bravo para trabajar como braceros en Estados Unidos. Si existen más de dos millones de chicos que piden limosna en las calles del país. Si la crisis económica ha obligado a que padre y madre trabajen y nuestros niños cada vez son más amamantados por la televisión. Si el $78 \%$ de las criaturas menores de cuatro años no alcanza la estatura y el peso normales debido a la desnutrición. Si antes de cumplir los cinco años, muere el $10 \%$ de la población infantil. Si el síndrome del niño golpeado ha aumentado un $30 \%$ en los últimos dos años. Si éste es el cuadro de vida de una gran mayoría de la niñez mexicana, cabe preguntar ¿por qué el proyectos de televisión dirigido a los infantes concentra su atención prioritariamente en las "televacaciones", las caricaturas agresivas, los programas de concursos infantiles, los comerciales para favorecer el consumismo y otras fantasías extranjeras, y no en impulsar el desarrollo humano de los pequeños? ${ }^{17}$

17 Usos comerciales de la televisión infantil, Uno Más Uno, 9 de enero de 1988; Diario 5 denuncias de maltrato de menores en Chihuahua: Miranda G., Excelsior, 29 de octubre de 1992; En 6 meses el DIF recibió 119 denuncias por maltrato infantil, El Financiero, 13 de septiembre de 1993; Es inexistente en México una politica que contemple a los niños. Ni siquiera ha sido planteada, Uno Más Uno, 27 de octubre de 1993.

Simplemente en la ciudad de León, Guanajuato, los casos de "violencia interfamiliar" -maltrato a los hijos, la mujer y el anciano- aumentó tanto que en 1993 se presentaron 30 denuncias por rapto, secuestro y tráfico de menores. Creciente violencia intrafamiliar se registra en León: Alcántara $S_{\text {, }}$, Excelsior, 22 de febrero de 1993. 


\section{¿Qué hacer?}

Dentro de este contexto modernizador de la sociedad mexicana podemos decir que aunque el Estado nacional cada día se esfuerza por ser mejor instancia rectora en el terreno de las relaciones económicas, políticas, ecológicas, internacionales, laborales, productivas, etc.; en el área cultural ha perdido la capacidad de conducción moral de nuestra sociedad. En este sentido, podemos decir que en los últimos decenios, en términos culturales el sector privado del país controlador los medios de comunicación y las corporaciones multinacionales, han sido las verdaderas secretarías de Estado que han influido en el intelecto y la emoción colectiva que han cohesionado al país.

Por ello, para corregir la dirección de nuestro espíritu nacional es fundamental estudiar el papel que desempeñan los medios electrónicos de comunicación, y particularmente la televisión, para diseñar nuevas políticas culturales, pues son esos canales los que están construyendo con mayor fuerza el proyecto mental cotidiano de la República. Dada la pérdida de la rectoría cultural de la sociedad mexicana por parte del gobiemo, actualmente es Razón de Estado el planificar el funcionamiento social de los medios de información masiva para el desarrollo del país. Tenemos que considerar que debido a la aceleradísima transformación global que vivimos, de nada servirá intentar corregir los pies económicos, los brazos tecnológicos, las manos laborales, el estómago agropecuario, los pulmones ecológicos del país, etc.; si no se modifica el alma mental que da vida a nuestra sociedad, pues el cuerpo, tarde o temprano, se volverá a desmoronar y cada vez mas con mayor profundidad.

\section{Documentación consultada}

Al maratón de Guadalajara 4,000, Excelsior, 4 de febrero de 1987.

Aplicarán hoy a 12 millones de infantes la vacuna antipolio, Excelsior, 24 de enero de 1987.

Aplicó la Armada 75 mil dosis de vacuna antipolio, Excelsior, 29 de enero de 1987. Bajaron los accidentes laborales en 57\%: IMSS, Excelsior, 10 de febrero de 1987. Cada vez más consumidores hacen valer sus derechos: Pliego Montes, Excelsior, 11 de febrero de 1987.

Creciente violencia intrafamiliar se registra en León: Alcántara S., Excelsior, 22 de febrero de 1993.

Del 26 al 30, vacunas contra el sarampión: SSA, Uno Más Uno, 20 de octubre de 1987. 
Medios de comunicación y transformación de ...

Descendió el analfabetismo a 7.6\%, Uno Más Uno, 27 de marzo de 1987.

Diario 5 denuncias de maltrato de menores en Chihuahua: Miranda G., Excelsior, 29 de octubre de 1992.

El paseo ciclista, un freno a la contaminación, Excelsior, 5 de junio de 1987.

El próximo sábado la segunda jornada de vacunación antipolio, Excelsior, 22 de marzo de 1986.

En 6 meses el DIF recibió 119 denuncias por maltrato infantil, El Financiero, 13 de septiembre de 1993.

Es inexistente en México una política que contemple a los niños. Ni siquiera ha sido planteada, Uno Más Uno, 27 de octubre de 1993.

Está preparando al FSTSE a 450 mil promotores del voto, Excelsior, 2 de julio de 1987. ESTEINOU MADRID, Javier. El estudio materialista de la comunicación de masas,

Cuadernos del Ticom No. 1, Taller de Investigación para la Comunicación Masiva, Departamento de Educación y Comunicación, Universidad Autónoma Metropolitana, Unidad Xochimilco, marzo de 1979, p.9.

ESTEINOU MADRID, Javier. La reconstrucción y los medios de Comunicación, El Búho, no. 15, suplemento cultural de Excelsior, 22 de diciembre de 1985.

ESTEINOU MADRID, Javier. Los medios de comunicación y la construcción de la hegemonia, Editorial Trillas, México, D.F., 1992, 200 páginas.

EsTEINOU MADRID, Javier. Televisión y memoria social (dos partes), El Búho Nos. 35

y 36, Excelsior, 11 y 18 de mayo de 1986.

Hoy 92 de cada 100 adultos mexicanos saben leer y escribir, Excelsior, 13 de diciembre de 1986.

La televisión sin cerillos quemó una casa, Excelsior, 7 de noviembre de 1993.

La televisión y los niños. Conocimiento de la realidad televisiva vs. conocimiento de la realidad nacional, Cuadernos del Consumidor, Instituto Nacional del Consumidor (INCO), México, D.F., noviembre de 1982.

La violencia televisada produce graves y prolongados daños síquicos en los niños, Excelsior, 8 de agosto de 1992.

La violencia televisada produce graves y prolongados daños síquicos en los niños, Excelsior, 8 de agosto de 1992.

La violencia televisada produce graves y prolongados daños síquicos en los niños, Excelsior, 8 de agosto de 1992.

Las campañas de vacunación han logrado reducir $35 \%$ las enfermedades infantiles, Excelsior, 12 de marzo de 1986. 
Killón y medio de niños serán vacunados contra la polio en el D.F., Excelsior, 21 de enero de 1987.

Reconocimiento de la UNESCO al gobierno mexicano por los resultados de programas de alfabetización, Uno Más Uno, 9 de septiembre de 1987.

Reconoció MMH el apoyo publicitario a las campañas del sector público, Excelsior, 29 de septiembre de 1987.

Respuesta al festival del donador altruista de sangre, Excelsior, 14 de octubre de 1987. Se inmunizó contra la polio a 12 de millones de infantes, Excelsior, 25 de enero de 1987. Serán inmunizados contra la polio más de doce millones de niños, Excelsior, 14 de enero de 1987.

Usos comerciales de la televisión infantil, Uno Más Uno, 9 de enero de 1988.

Vacunados más de 10 millones de niños contra difteria y tosferina, Excelsior, 23 de mayo de 1987. 